\title{
Pelatihan Editing Photo Dengan Adobe Photosop Di Sman Gumay
}

\author{
Ferry Putrawansyah \\ Program Studi Teknik Informatika; Sekolah Tinggi Teknologi Pagaralam (STTP) \\ Jl. M. Siagim No.75 Kel. Karang Dalo, Dempo Tengah, Kota Pagar Alam \\ Telp/Fax: (0730) 621916
}

e-mail: feyputrawansyah@gmail.com.

\begin{abstract}
Abstrak
SMAN Gumay merupakan lembaga pendidikan yang berada di daerah cukup terpencil dan jauh dari Kota Kabupaten Lahat, Sebagai Sekolah Menengah Atas, SMA Gumay dituntut untuk memberikan pendidikan menengah umum juga dapat memberikan softskils yang lebih spesifik sehingga pengelola SMA Gumay memiliki rasa tanggungjawab, bersama STTP yang memiliki semangat untuk berbagi berdasarkan semangan pelaksanaan Tri Dharma, berdasarkan survey maka Civitas STTP diminta untuk melatih siswa aplikasi editing photo dengan software photoshop, yang mana pelatihan menggunakan metode pelatihan langsung praktek, agar pelatihan berjalan tepat sasaran pelatihan maka dilakukan tes untuk mengetahui tingkat pemahaman siswa peserta pelatihan, maka dilakukan post dan pre tes, pelaksanaan pelatihan diawali dengan pengenalan teknologi computer, dasar-dasar multimedia, pengolahan citra (gambar), pengenalan fitur photoshop, baru pelatihan dan contoh-contoh pengaplikasian fitur, siswa peserta diminta mengedit photo dan terakhir Tanya jawab. Dari hasil pre dan pos tes diketahui bahwa pemahaman siswa peserta terhadap teknologi computer sangat kurang bahkan ada siswa yang belum pernah menggunakan aplikasi computer dan setelah pelatihan peserta memahami sangat baik materi yang disampaikan dan sangat merasa mudah dalam mengolah photo (gambar), sehingga memiliki ketertarikan pada pelajaran komputer dan memiliki ketertarikan untuk studi lanjut pada STTP.
\end{abstract}

Kata kunci-Pelatihan, berbagi, softskills, word, Pengabdian, narasumber, Materi.

\section{PENDAHULUAN.}

Teknologi pengolahan gambar (photo) dan multimedia semakin berperan dalam keseharian, untuk mengabadikan kehidupan sangat diperlukan pembelajaran pengolahan gambar yang baik, hal ini diperlukan bila pada saat misalnya pengambilan gambar tidak terlalu bagus maka harus diolah hingga gambar menjadi nyaman pada saat dilihat [2], perkembangan pengolahan gambar (photo) dilatar belakangi perkembangan teknologi informasi dan komunikasi (TIK) khususnya teknologi yang mendukung terlaksananya berbasis komputer saat ini sangat banyak dan menawarkan kemudahan sesuai ke unggulan masing-masing [3][7], salah satunya adobe photoshop yang bisa di manfaatkan sebagai sarana pembuatan aplikasi pengolahan data photo. Media ini sangat banyak sekali digunakan di sebagai sarana pengolahan data yang sangat familiar.

Aplikasi adobe photoshop sebagai media (sarana) pembuatan aplikasi pengolahan data photo sangat di sarankan karena memiliki menu-menu yang sesuai dengan standar penulisan yang di sarankan para ahli yang kompeten [4], sehingga pada saat penyusunan pada adobe photoshop ini pembuat aplikasi tinggal klik menu yang di maksud maka akan di dapat hasil tulisan (hitungan/pengolah data) yang baik (standar), selain itu adobe photoshop merupakan software pengolah data yang mudah, apa bila ingin meng-upgrade [5], atau mengganti ke versi terbaru Microsoft menyediakan dengan mudah.

Dari pemaparan diatas dituntut agar para siswa dan pemuda harus selalu meningkatkan kualitas pembelajaran dengan menggunakan semua resource terkait [6], sehingga dipandang perlu untuk diadakan pelatihan pembuatan aplikasi pengolahan data photo ini, dan SMAN 
Gumay menangkap peluang ini dengan mengijinkan kepada civitas akademika STTP untuk melakukan pengabdian dengan mengadakan pelatihan pengolahan gambar dengan Photoshop, sehingga STTP melalui LPPM mengutus dosen untuk melakukan pelatihan.

\section{METODE.}

Pelaksanaan pengabdian ini dilakukan dosen STTP dilakukan secara mandiri, dan berbarengan dengan kuliah kerja nyata yang dilakukan mahasiswa sehingga dalam pelaksanaanya mahasiswa membantu dosen yang melaksanakan pengabdian [9]. Metodologi yang digunakan pada pelaksanaan kegiatan Pengabdian kepada masyarakat (PkM) ini adalah menyimak (menonton) bersama, membaca bersama (modul pelatihan), memahami tools aplikasi (Software) dan berinteraksi secara langsung (Aplikatif) dengan software.

\subsection{Pengabdian Pada Masyarakat (PkM).}

Pengabdian masyarakat adalah suatu kegiatan yang bertujuan membantu masyarakat tertentu dalam beberapa aktivitas tanpa mengharapkan imbalan dalam bentuk apapun. Secara umum program ini dirancang oleh berbagai universitas atau institut yang ada di Indonesia untuk memberikan kontribusi nyata bagi bangsa Indonesia, khususnya dalam mengembangkan kesejahteraan dan kemajuan bangsa Indonesia. Kegiatan Pengabdian Masyarakat (PkM) merupakan salah satu bagian dari Tri Dharma Perguruan Tinggi. Bentuk-bentuk kegiatan Pengabdian Masyarakat: Bakti Sosial dan Mengajar. Tujuan Pengabdian Masyarakat di Perguruan Tinggi (PT):

1. Menciptakan inovasi teknologi untuk mendorong pembangunan ekonomi Indonesia dengan melakukan komersialisasi hasil penelitian;

2. Memberikan solusi berdasarkan kajian akademik atas kebutuhan, tantangan, atau persoalan yang dihadapi masyarakat, baik secara langsung maupun tidak langsung;

3. Melakukan kegiatan yang mampu mengentaskan masyarakat tersisih (preferential option for the poor) semua strata, yaitu masyarakat tersisih secara ekonomi, politik, sosial \& budaya;

4. Melakukan alih teknologi, ilmu, dan seni kepada masyarakat untuk pengembangan martabat manusia dan kelestarian sumber daya alam.

\subsection{Multimedia atau Edit Photo.}

Multimedia merupakan penggunaan komputer untuk menyajikan dan menggabungkan teks, suara, gambar, animasi, audio dan video dengan alat bantu (tool) dan koneksi (link) [7] sehingga pengguna dapat melakukan navigasi, berinteraksi, berkarya dan berkomunikasi [1]. Multimedia sering digunakan dalam dunia informatika. Selain dari dunia informatika, multimedia juga diadopsi dunia game, dan juga bahkan untuk membuat website.

Multimedia berasal dari pada kata 'multi' dan 'media'. Multi berarti banyak, dan media bererti tempat, sarana atau alat yang digunakan untuk menyampaikan informasi [8]. Jadi berdasarkan kata 'multimedia' dirumuskan sedagai wadah atau penyatuan beberapa media kemudian didefinisikan sebagai elemen-elemen pembentukan multimedia [10]. Elemen-elemen tersebut seperti teks, gambar, suara, animasi, dan video. Multimedia merupakan suatu konsep dan teknologi baru bidang teknologi informasi, di mana informasi dalam bentuk teks, gambar, suara, animasi, dan video disatukan dalam komputer untuk di simpan, diproses dan disajikan baik secara liner maupun interaktif. Oleh itu, dengan menggabungkan seluruh elemen multimedia tersebut menjadikan informasi dalam bentuk multimedia yang dapat diterima indera penglihatan dan pendengaran, lebih mendekati bentuk aslinya dalam dunia sebenarnya. Multimedia enteraktif apabila suatu aplikasi terdapat seluruh elemen multimedia yang ada dan pemakai (user) diberi keputusan atau kemampuan untuk mengawal dan menghidupkan elemen-elemen tersebut. Pengertian Multimedia Menurut Para Ahli

a. Menurut McCormick (1996), Multimedia adalah kombinasi tiga elemen, suara \& gambar.

b. Menurut Rosch (1996), Multimedia sebagai kombinasi dari komputer dan video.

c. Menurut Gumelar (2014), Multimedia adalah penggunaan komputer untuk menyajikan dan menggabungkan teks, animasi, suara, gambar dan video dengan tools (alat bantu) dan link sehingga pengguna dapat melakukan navigasi, interaksi, berkarya dan berkomunikasi. 
Multimedia dimanfaatkan juga dalam dunia pendidikan dan bisnis. Pada dunia pendidikan, multimedia digunakan sebagai media pengajaran, baik dalam kelas maupun secara sendiri atau otodidak. Di dunia bisnis, multimedia digunakan sebagai media profil perusahaan, profil produk, bahkan sebagai media kios informasi dan pelatihan dalam sistem e-learning.

Pada awalnya multimedia hanya mencakup media yang menjadi konsumsi indra penglihatan (gambar diam, teks, gambar gerak video, dan gambar gerak rekaan/animasi), dan konsumsi indra pendengaran (suara) dan juga berupa (berwujud). Dalam perkembangannya multimedia mencakup juga kinetik (gerak) dan bau yang merupakan konsumsi indra penciuman. Multimedia mulai memasukkan unsur kinetik sejak diaplikasikan pada pertunjukan film 3 dimensi yang digabungkan dengan gerakan kursi tempat duduk penonton. Kinetik \& film 3 dimensi membangkitkan sense realistis.

Bau mulai menjadi bagian dari multimedia sejak ditemukan teknologi reproduksi bau melalui telekomunikasi. Dengan perangkat input pendeteksi bau, seorang operator dapat mengirimkan hasil digitizing bau tersebut melalui internet. Komputer penerima harus menyediakan perangkat output berupa mesin reproduksi bau. Mesin reproduksi bau ini mencampurkan berbagai jenis bahan bau yang setelah dicampur menghasilkan output berupa bau yang mirip dengan data yang dikirim dari internet. Dengan menganalogikan dengan printer, alat ini menjadikan feromonferomon bau sebagai pengganti tinta. Output bukan berupa cetakan melainkan aroma.

\section{SEJARAH PERKEMBANGAN MULTIMEDIA}

Lewat tahun 70-an, penggunaan mikro komputer di rumah dan pejabat telah dapat membantu pengguna menyelesaikan masalah-masalah sistem yang sosfitikated bagi mempercepatkan pengguna menyelesaikan aktiviti-aktiviti kerja harian. Penggunan komputer juga membolehkan penyebaran maklumat dilakukan dan memberi hiburan kepada pengguna.

\section{PERKEMBANGAN MULTIMEDIA SELARAS PERUBAHAN TEKNOLOGI KOMPUTER.}

Pada tahun 60-an, komputer rangka (main frame computer), digunakan untuk mengendalikan pangkalan data korporat yang besar. 1970-an, terminal komputer digunakan organisasi untuk menyebar dan menguruskan maklumat. Era 1980-an, rekabentuk komputer diubah sesuai dimana ia menjadi lebih mudah digunakan. Semua orang boleh memiliki komputer untuk melakukan kerja pemrosesan perkataan, prediksi, game komputer dan sebagainya. 1980-1990 an, perkembangan penciptaan komputer semakin drastik sehingga mencapai tahap yang tidak tergambar sebelum ini. Dalam masa yang sama, perkembangan teknologi ini telah membawa kepada :
a. Menghasilkan mikro komputer (desktop) dengan kelajuan pemproses yang lebih cepat.
b. Meningkatkan kapasiti memori kerja di dalam komputer.
c. Kapasitas muatan data yang lebih besar di dalam hardisk dan CD-ROMs.
d. Audio dan video digital.
e. Sistem operasi bergrafik memudahkan pengguna menggunakan penunjuk atau klik pada objek dengan menggunakan mouse. Arahan berasaskan antaramuka pengguna bergrafik memudahkan pengguna melakukan proses-proses yang dikehendaki dengan lebih mudah.
f. Rangkaian LAN dan WAN secara meluas membolehkan users berhubung di seluruh dunia.

\section{MULTIMEDIA DAN KESANNYA KEPADA INDUSTRI}

Perkembangan teknologi Multimedia memberi kesan pada 3 bidang industri :
a. Industri komputer (computing)
b. Industri telekomunikasi (telecommunication) dan
c. Industri penyiaran (broadcasing)

\section{KESAN KEPADA INDUSTRI KOMPUTER}

Maklumat komputer tidak lagi dipersembahkan melalui teks dan grafik, tetapi juga melalui sumber yang diperoleh dari media lain seperti audio dan video. Sistem komputer multimedia telah banyak berubah untuk memastikan ia berkemampuan menukar sebarang maklumat dalam keadaan analog seperti suara, musik dan video ke format digital dan kemudiannya menukar semula data yang berada dalam bentuk digital ke bentuk analog apabila diperlukan. Berbagai jenis media input telah dikeluarkan untuk membolehkan data multimedia disimpan. Wujudnya berbagai model baru yang 
membenarkan komputer mengeksekusi sistem multimedia serta rekayasa oleh seseorang sistem atau end user. Data dari berbagai media atau sumber perlu diintegrasikan supaya dapat melaksanakan sesuatu tugas. Cara maklumat dipersembahkan telah berubah. Selain penggunaan kertas dan komputer, maklumat multimedia dipersembahkan melalui speaker atau di record terus ke peranti video.

\section{MULTIMEDIA PADA INDUSTRI TELEKOMUNIKASI}

Maklumat multimedia juga dapat dibagi melalui rangkaian komputer atau penghantaran wireless (satelit). Oleh kerena maklumat multimedia selalunya bersize besar dan dalam keadaan continous, kaedah penghantaran data yang sesuai amat diperlukan. Ini mengakibatkan perubahan kepada sistem telekomunikasi yang ada. Sistem rangkaian yang dahulunya hanya menggunakan telefon yang membawa sedikit data dan lambat (yakni $<28 \mathrm{kbit}$ ), kini telah berubah kepada talian lease yang lebih banyak data dihantar seperti 2Mbit, 10Mbit dan 622Mbit (contohnya di MSC).

\section{MULTIMEDIA PADA INDUSTRI PENYIARAN}

Pada awalnya, peralatan professional bagi audio dan video terdapat di studio rekaman dan dibagai penyiaran televise saja. Perubahan telah berlaku kepada peralatan tersebut, dimana sistem-sistem yang lebih professional telah digunakan untuk pengeditan movie secara digital. Maklumat yang dihasilkan juga disiarkan dengam kaedah penyiaran seperti kabel, satelit dan antenna. Fenomena ini memungkinkan industri penyiaran ini menjadi penyumbang maklumat (information provider) kepada pengguna melalui rangkaian komputer.

\section{BIDANG PENGGUNAAN MULTIMEDIA}

Teknologi Multimedia digunakan pada berbagai bidang. Bidang, antara lain: Perniagaan, Pendidikan, Penyiaran, Hiburan, politik dan sebagainya.

\section{MULTIMEDIA BIDANG PERNIAGAAN}

Perniagaan memerlukan komunikasi, secara tradisinya dalam perniagaan boleh dilakukan secara :
a. Verbal
b. Dari seorang ke seorang
c. Dalam bentuk cetakan
d. Menggunakan slide show
e. Menggunakan video

Multimedia berupaya untuk meniru setiap cara komunikasi yang di sampaikan serta dapat menggabungkannya supaya menjadi satu tarikan yang lebih menarik. Aplikasi multimedia yang terlibat dalam bidang perniagaan ini termasuk:
a. Persembahan jualan (sales/market presentations).
b. Trade-show production
c. Sistem latihan pekerja.
d. Direct marketing
e. Retail vending
f. Point-of-sale information

\section{MULTIMEDIA BIDANG PEMERINTAHAN}

Teknologi multimedia bisa dimanfaatkan dalam bidang pengelolaan Negara (governance) seperti

a. Perintah elektronik atau paperless office

b. Keperluan pertahanan Negara

c. Penyebaran informasi kepada masyarakat

\section{MULTIMEDIA PADA BIDANG PENDIDIKAN}

Bidang pendidikan dilihat sebagai suatu bidang yang paling layak untuk menggunakan teknologi multimedia. Komputer multimedia boleh menggabungkan animasi, video dan audio bersama-sama teks dan grafik, serta berupaya untuk melaksanakan interaktivitas yang membolehkan proses pembelajaran dan pengajaran dilakukan dengan lebih berkesan. Dengan sistem multimedia, pihak pengajar boleh mengesan prestasi pelajar dengan memperoleh laporan setiap kali pelajar 
menggunakan bahan tersebut. Pendidikan juga boleh berlaku dirumah. Program pendidikan jarak jauh juga boleh dilaksanakan oleh institusi-institusi perguruan tinggi untuk menggalakkan lebih mudah ke masyarakat mempunyai ijazah diperingkat lebih tinggi.

\section{MULTIMEIDA DI BIDANG PENYIARAN}

Teknologi multimedia juga bisa dimanfaatkan pada bidang penyiaran seperti :
a. Pengiklanan
b. Pembuatan film animasi atau stunt.
c. Peralatan audio dan video

\section{MULTIMEDIA PADA HIBURAN}

Teknologi multimedia juga banyak digunakan dalam bidang hiburan. Banyak permainan kini terdapat dalam bentuk bundle tertentu dan mengandungi elemen-elemen grafik, animasi, audio dan video. Bentuk permainan yang ganas dan tidak berfaedah harus dibendung. Kini terdapat juga permainan atau game yang mempunyai unsur-unsur pendidikan. Perkataan edutaiment dirujuk sebagai education dan entertaiment. Permainan atau game ini mengajar kita supaya membuat perancangan dengan teliti dan mengasah orak mengira dengan betul, sambil berhibur. Video-ondemand merupakan satu lagi aplikasi multimedia berupa hiburan. Pengguna boleh memilih manamana rancangan yang terdapat dalam perpustakaan rancangan-rancangan dan boleh menontonnya pada masa yang dikehendaki. Pelanggan boleh mendapatkan apa-apa bahan sesuai minat masingmasing asalkan ia terdapat di dalam server.

\subsection{Photoshop.}

Adobe Photoshop, atau biasa disebut Photoshop, merupakan perangkat lunak editor citra buatan Adobe Systems yang dikhususkan untuk pengeditan foto/gambar dan pembuatan efek. Perangkat lunak ini banyak digunakan fotografer digital dan perusahaan iklan sehingga dianggap sebagai pemimpin pasar (market leader) untuk perangkat lunak pengolah gambar/ foto, dan, bersama Adobe Acrobat, dianggap sebagai produk terbaik yang pernah diproduksi Adobe Systems. Versi kedelapan aplikasi ini disebut dengan nama Photoshop CS (Creative Suite), versi sembilan disebut Adobe Photoshop CS2, versi sepuluh disebut Adobe Photoshop CS3, versi kesebelas merupakan Adobe Photoshop CS4, versi keduabelas adalah Adobe Photoshop CS5, versi ketigabelas adalah CS6, dan versi terbaru merupakan Adobe Photoshop CC.

\subsection{Pre \& Pos Tes.}

\section{Pre Test.}

Pre tes yaitu suatu bentuk pertanyaan, yang diberikan guru pada muridnya sebelum memulai suatu pelajaran. Pertanyaan yang ditanya adalah materi yang akan diajar pada hari itu (materi baru). Pertanyaan biasanya dilakukan guru di awal pembukaan pelajaran. Pre test diberikan dengan maksud untuk mengetahui apakah ada diantara murid yang sudah mengetahui mengenai materi yang akan diajarkan. Pre test juga bisa di artikan sebagai kegiatan menguji tingkatan pengetahuan siswa terhadap materi yang akan disampaikan, kegiatan pre test dilakukan sebelum kegiatan pengajaran diberikan. Adapun manfaat dari diadakannya pre test untuk mengetahui kemampuan awal siswa mengenai pelajaran yang disampaikan. Dengan mengetahui kemampuan awal siswa ini, guru dapat menentukan cara penyampaian pelajaran yang akan di tempuhnya nanti.

\section{Post Test.}

Post test merupakan bentuk pertanyaan yang diberikan setelah pelajaran/materi telah disampaikan. Singkatnya, post test merupakan evalausi akhir saat materi yang di ajarkan pada hari itu telah diberikan yang mana seorang guru atau pengajar memberikan post test dengan maksud apakah murid sudah mengerti dan memahami mengenai materi yang baru saja diberikan pada hari itu. Manfaat dari diadakannya post test ini untuk memperoleh gambaran tentang kemampuan yang dicapai setelah berakhirnya penyampaian pelajaran. Hasil post test ini dibandingkan dengan hasil pree test yang telah dilakukan sehingga akan diketahui seberapa jauh efek atau pengaruh dari pengajaran yang dilakukan, disamping 
sekaligus dapat diketahui bagian bagian mana dari bahan pengajaran yang masih belum dipahami sebagian besar siswa.

\subsection{Penyelesaian Masalah.}

Sehingga sesui dengan permasalahan ini maka perlu dilakukan pelatihan editing gambar (photo) menggunakan aplikasi yang familiar, ini di yakini bisa menambah softskills dan kepercayaan diri alumni SMA Gumay sehingga tidak hanya masalah atau pelajaran umum saja yang dipahaminya tetapi mendapat pelajaran tambahan dalam menghadapi perkembangan zaman pada masyarakat [11].

\section{PEMBAHASAN DAN HASIL.}

3.1. Realisasi \& Pemecahan Masalah.

Maka berdasarkan cara penyelesaian masalah yang dijadikan acuan, maka berikut merupakan langkah-langkah pelaksanaan pengabdian yang sudah dilakukan oleh pengabdi, yang mana pada dilaksanakan secara berurut sebagai berikut:

Tabel 1. Rician Kegiatan Pelatihan

\begin{tabular}{|c|c|l|l|}
\hline Pelaksanaan & Waktu & \multicolumn{1}{|c|}{ Materi } & Penyaji \\
\hline \multirow{5}{*}{ 1 Hari } & $\begin{array}{c}08.00-09.00 \\
09.00-09.30\end{array}$ & $\begin{array}{l}\text { Pre Test } \\
\text { Persiapan Membuat Aplikasi } \\
\text { pengolah data photo }\end{array}$ & Ferry \\
\cline { 2 - 4 } & $09.30-12.00$ & $\begin{array}{l}\text { Panduan Membuat aplikasi dan } \\
\text { Tutorial Membuat aplikasi pengolah } \\
\text { data photo }\end{array}$ & Putrawansyah \\
& $12.00-12.30$ & $\begin{array}{l}\text { Ishoma } \\
\text { Post-test }\end{array}$ & \\
\hline
\end{tabular}

Sehingga berdasarkan langkah pelaksanaan pengabdian diatas dari metode pelaksanaan yang dilakukan pada saat pengabdian yang mana pelatihan dilakukan dengan seperti seminar, dilakukan dengan menjelaskan materi tentang pengolahan data photo, yang dalam hal ini pembahasan adalah bagaimana mengedit photo sehingga kualitasnya makin baik dan diinginkan, yang mana struktur pelaksanaannya sesuai dengan tabel diatas, didahului dengan melakukan pre tes untuk memahami tingkat pemahamaan terhadap teori editing dan pemahaman tentang multimedia editing photo, setelah dilakukan tes selanjutnya dilakukan persiapan pengolahan, persiapan ini melakukan pengenalan terhadap fitur-fitur photoshop dan memberikan contoh bagaimana melakukan aplikasi terhadap fitur-fitur yang ada tersebut, sampai para peserta memahaminya seluruh fungsi dari fitur yang ada untuk digunakan pada saat melakukan editing photo.

Setelah seluruh peserta pelatihan paham dan mengerti cara mengaplikasikan fitur-fitur yang ada dalam mengolah gambar ( $p h o t o$ ), agar lebih baik lagi pemahaman para peserta pelatihan dalam hal ini maka selanjutnya dilakukan pendampingan pengolahan secara langsung terhadap data gambar atau photo yang dimiliki dengan aplikasi mengolah atau melakukan pelatihan editing secara langsung, para peserta mengaplikasikan pemahamannya pada saat mengolah data gambar, dan narasumber secara langsung membimbing dan mendampingi para peserta melakukan editing photo, sehingga para peserta dengan mudah mengaplikasikan pelajaran secara langsung dan pada saat ada masalah atau kesulitan peserta langsung bertanya pada pelatih atau narasumber secara langsung, sehingga peserta benar-benar paham dan benar-benar bisa melakukan editing photo dengan menggunakan aplikasi photoshop.

Setelah secara terstruktur dan terurut pelaksanaan pengabdian dilakukan sebenarnya pengabdi sudah menyakini bahwa peserta pelatihan telah memiliki pemahaman dan pengetahuan yang baik dalam mengolah atau mengedit photo, tetapi secara prosedur harus dilakukan tes lagi untuk mengetahui lebih procedural tingkat pemahaman peserta dalam menyerap materi maka dilakukan pos tes, hasilnya $100 \%$ peserta pelatihan memahami materi dan pelatihan edit photo dengan sangat baik, yang mana pada awalnya mereka tidak memahami sama sekali tetapi metode 
belajar secara langsung pada aplikasi meningkatkan semangat peserta untuk belajar, dengan belajar secara langsung ternyata sangat mengena dengan keinginan peserta pelatihan.

\subsection{Pembahasan \& Hasil.}

Berdasarkan urutan pelaksanaan pengabdian yang dilaksanakan diatas yang terdeskripsi didalam tabel 1. Maka berikut ini merupakan uraian keberhasilan yang didapatkan dari pelaksanaan pengabdian yang dilaksanakan pada SMAN Gumay adalah sebagai berikut, yang mana pada pelaksanaannya peserta harus diberikan pemahaman bukan hanya aplikasi tetapi pemahaman dasar tentang multimedia dan software-software pendukung lainnya yang mendukung dalam melakukan editing terhadap photo atau pun video.

Tabel 2. Keberhasilan Pelaksanaan Kegiatan

\begin{tabular}{|c|l|l|}
\hline Pertemuan & \multicolumn{1}{|c|}{ Materi } & \multicolumn{1}{c|}{ Hasil } \\
\hline 1 & $\begin{array}{l}\text { Pengenalan teori pengolahan } \\
\text { gambar, video dan multimedia }\end{array}$ & $\begin{array}{l}\text { Peserta memahami dengan baik teori dan } \\
\text { logika pengolahan data gambar, video dan } \\
\text { multimedia. }\end{array}$ \\
\hline 2 & $\begin{array}{l}\text { Pengenalan software buat } \text { edit } \\
\text { photo dan video }\end{array}$ & $\begin{array}{l}\text { Para peserta menjadi paham software apa } \\
\text { saja yang bisa dimanfaatkan pada saat } \\
\text { mengolah gambar dan mampu } \\
\text { mengelompokan berdasarkan fungsi serta } \\
\text { manfaat aplikasi tersebut. }\end{array}$ \\
\hline 3 & $\begin{array}{l}\text { Pengenalan tools dan fitur } \\
\text { photoshop }\end{array}$ & $\begin{array}{l}\text { Hasilnya peserta pelatihan mengetahui nama } \\
\text { dan fungsi seluruh tools dan fitur yang ada } \\
\text { pada photoshop dan buat apa aplikasinya. }\end{array}$ \\
\hline 5 & $\begin{array}{l}\text { Memberikan contoh } \\
\text { pengaplikasian fitur photoshop } \\
\text { Melakukan percobaan aplikasi } \\
\text { atau melakukan } \text { edit photo } \\
\text { secara langsung dengan } \\
\text { photoshop }\end{array}$ & $\begin{array}{l}\text { Peserta pelatihan melihat dan paham bahkan } \\
\text { bisa mengaplikasikan tools yang ada buat } \\
\text { mengolah data gambar. }\end{array}$ \\
\hline $\begin{array}{l}\text { Seluruh peserta bisa mengaplikasikan } \\
\text { photoshop untuk kebutuhannya dan } \\
\text { melakukan edit terhadap photo yang dimiliki } \\
\text { dengan hasil baik dan memuaskan. }\end{array}$ \\
\hline
\end{tabular}

Dari sini bisa di pahami hasil dari kegiatan pengabdian yang dilakukan ini softskills para peserta siswa dan siswi yang mengikuti pelatihan meningkat dengan sangat baik dan pelatihan berhasil dengan sangat baik, sehingga peserta pelatihan menjadi lebih optimis dalam menghadapi masa depannya ini memberikan keuntungan bagi SMAN Gumay karena masyarakat semakin percaya dan bagi STTP dengan pengabdian dan pelatihan ini mendapat calon atau peminat baru untuk kuliah di STTP dan lebih meningkatkan kepercayaan pada kemampuan alumni yang sangat baik, sehingga bisa diidentifikasi berikut merupakan hasil akhirnya, yaitu:

a. Para peserta siswa dan siswi SMAN Gumay mempunyai pengetahuan dan pemahaman yang baik tentang multimedia dan pengolahan photo dengan photoshop.

b. Seluruh siswa dan siswi SMAN Gumay menjadi sangat paham terhadap teknologi informasi yang lebih aplikatif untuk mendukung dalam pengolahan data yang diperlukannya, missal dalam hal edit photo.

c. Para guru SMAN Gumay sudah terbantu dalam pemberian pemahaman terhadap teknologi informasi up to date yang aplikatif.

d. Para siswa dan siswi peserta pelatihan lebih memahami lagi tentang aplikasi pembelajaran TIK yang disampaikan guru didalam kelas, jauh lebih memahami secara lebih aplikatif dalam mengolah data gambar.

e. Para siswa siswi peserta pelatihan menjadi lebih merasa percaya diri saat terjun pada dunia kerja dan lebih memiliki pemahaman pada siswa dan siswi yang melanjutkan studi 
keperguruan tinggi jelas pembelajaran ini menjadi pemahaman awal dalam bergaul pada perkuliahan di kampus.

\section{KESIMPULAN}

Pada pelaksanaan pengabdian masyarakat $(\mathrm{PkM})$ ini yang dilakukan di SMAN Gumay dengan tujuan melatih siswa dan siswi dalam melakukan editing terhadap data gambar atau photo didapatkan kesimpulan sebagai berikut:
a. Melakukan proses pembelajaran dengan cara belajar aplikasi secara langsung ternyata sudah mampu meningkatkan semangat siswa belajar menjadi lebih baik (giat).
b. Menambah softskills siswa-siswi SMA Gumay
c. Meningkatkan rasa percaya diri siswa dengan kemampuannya ketika terjun di masyarakat.
d. Membantu guru pelajaran TIK dalam hal memahamkan siswa terhadap suatu aplikasi tertentu.

\section{SARAN}

Maka berdasarkan pengalaman yang dilihat dan dirasakan penulis saat melakukan pengabdian ini maka, penulis dalam hal ini bisa memberikan saran:

a. Waktu pengabdian dilakukan lebih lama

b. Materi ditambah/ lebih kompleks dan lebih banyak contoh.

\section{UCAPAN TERIMA KASIH}

Penulis mengucapkan terima kasih kepada Panitia KKN dan Pengabdian bagi Dosen, terima kasih kepada keluarga, kawan-kawan dosen.

\section{DAFTAR PUSTAKA}

[1] Muslim, B. 2018. Pelatihan aplikasi editing video dengan filmora., Laporan Pengabdian Kepada Masyarakat, LPPM STT Pagaralam.

[2] Muslim, B. 2018. Pelatihan Pembuatan Blog Bagi Guru Ma Ponpes Darul Mutaqin Kota Pagaralam. NGABDIMAS. Vol 1. No.1. Bulan Juni, Hal. 6-11

[3] B. Muslim, Pengantar teknologi informasi. Yogyakarta: Deepublish, 2017.

[4] Muslim, B. (2018). Analisis system informasi (SI) terintegrasi di Perguruan Tinggi (PT) (Studi Kasus: STT Pagaralam). Jurnal Teknologi Informasi MURA, Vol 10. Page 83-91.

[5] Muslim, B (2014). Analisis rencana aplikasi teknologi informasi pada STT Pagar Alam. Proseding semnastik dan Magma. Issue: Aplikasi Teknologi dan sistem Informasi. PPP UBD Pres. Pages 397-404.

[6] Hutchinson E. Sarah and Sawyer C. Stacey, 2000, Computers, Communications \& Information, McGraw Hill Companies Inc.

[7] Indonesia Services Education HP Tim, 2001, Manajemen Sistem Belajar Di Dunia Maya, Majalah Info Komputer.

[8] M.H Jogiyanto, 1995, Pengenalan Komputer, Andi Offset Yogyakarta.

[9] Horsley, M., Knight, B., \& Huntly, H. 2010. The role of textbooks and other teaching and learning resources in higher education in Australia: Change and continuity in supporting learning. IARTEM 1-Journal. 3(2). 43-61.

[10] Sadiman, A.S., Rahardjo, R., Haryono, A., \& Rahardjito. 2006. Media pendidikan: Pengertian, pengembangan, dan pemanfaatan. Jakarta: Rajagrafindo Persada.

[11] Menristekdikti. 2016. Panduan Pelaksanaan Penelitian dan Pengabdian Masyarakat di Perguruan Tinggi Edisi X Tahun 2016. hlm. 4

[12] Isro'Mukti, Y. (2017). Sistem Informasi Madrasah Aliyah Negeri Pagar Alam Berbasis Web. Indonesian Journal of Computer Science, 6(2), 192-205.

[13] Mukti, Y. (2017). Perencanaan Strategis Sistem Informasi Dan Teknologi Informasi Pada 
Sekolah Menengah Kejuruan Negeri 2 Pagar Alam. JURNAL ILMIAH BETRIK: Besemah Teknologi Informasi dan Komputer, 8(02), 83-92.

[14] Arif, A., \& Mukti, Y. (2017). Rancang Bangun Website Sekolah Menengah Pertama (SMP) Negeri 8 Kota Pagar Alam. JURNAL ILMIAH BETRIK: Besemah Teknologi Informasi dan Komputer, 8(03), 156-165.

[15] Isro'Mukti, Y. (2018, October). Sistem Informasi Manajemen Aset Sekolah Tinggi Teknologi Pagaralam Berbasis Web. In Seminar Nasional Teknologi Informasi dan Komunikasi (SEMNASTIK) (Vol. 1, No. 1, pp. 632-638).

[16] Mukti, Y. (2018). Rancang Bangun Website Sekolah Dengan Metode User Centered Design (UCD). JURNAL ILMIAH BETRIK: Besemah Teknologi Informasi dan Komputer, 9(02), 84-95.

[17] Mukti, Y. (2018). Pelatihan Maintance Komputer SMAN Pagar Gunung. NGABDIMAS, $1(1), 47-51$. 